Principal Investigator: Prof. W. Jason Weiss, Purdue University, wjweiss@purdue.edu, 765.494.2215

Program Office: jtrp@purdue.edu, 765.494.6508,www.purdue.edu/jtrp

Sponsor: Indiana Department of Transportation, 765.463.1521

SPR-3611

\title{
Performance of Portland Limestone Cements: Cements Designed to Be More Sustainable That Include up to $15 \%$ Limestone Addition
}

\section{Introduction}

In 2009, ASTM and AASHTO permitted the use of up to $5 \%$ interground limestone in ordinary portland cement (OPC) as a part of ASTM C150/AASHTO M85. When this project was initiated, a new proposal was being discussed that would enable up to $15 \%$ interground limestone to be considered in ASTM C595/ AASHTO M240 cement. This project was initiated to provide rapid feedback to INDOT for use in discussions regarding these specifications. This information was provided during the project and this report documents those findings.

The proposal for increasing the volume of limestone that would be permitted to be interground in ASTM C595/AASHTO M240 cement is designed to enable more sustainable construction which may significantly reduce the $\mathrm{CO} 2$ that is embodied in the built infrastructure while extending the life of cement quarries. Further, as Indiana is a large producer of limestone based products it may be possible to use limestone as a part of the binder and not just a filler. This could alter both environmental and economic considerations for the concrete in transportation structures for use in paving (Figure 1) or transportation structure applications.

Significant research regarding the properties with interground limestone has been conducted by the cement industry since these cements became widely used in Europe over three decades ago. Recently, two main reviews of this work have been developed for application in North America. ${ }^{1}$ Based on these reviews, it was determined that further studies be performed to understand how low temperature sulfate attack can occur and to

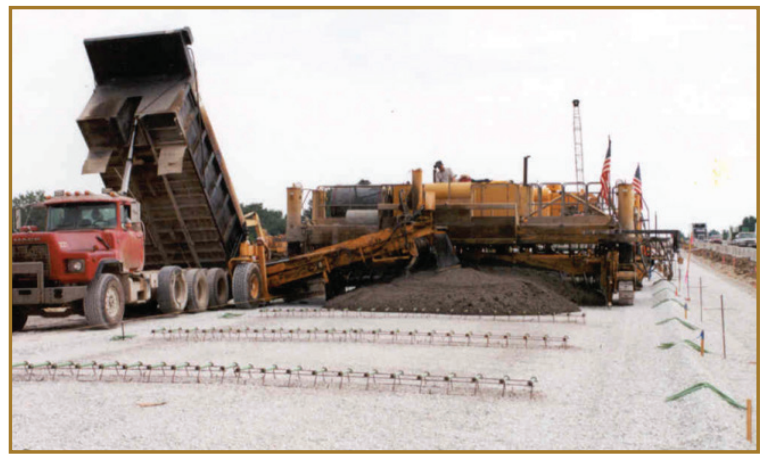

Figure 1. Typical PCCP paving. understand the impact of exposure to high concentrations of deicing salts on joint deterioration. Research to address the concern of sulfate attack is being performed under the direction of Hooton at Toronto and Thomas at New Brunswick. Research to address the potential impact of exposure to high concentrations of deicing salts is ongoing at Purdue University. The present work focuses on North American PLCs, designed to be equivalent replacements for OPC, and performs a series of tests that will be of interest in terms of early age and standard DOT tests.

\section{Findings}

The physical and chemical properties of the cementitious materials used in this study were examined. Intergrinding the limestone with portland cement clinker (to make PLC that is consistent with ASTM C595/AASHTO M240) is primarily a physical process that does not appear to result in any chemical alterations of the portland cement clinker. Intergrinding the limestone with the clinker results in a finer powder with a reduction in the coarse clinker particles $(>20 \mu \mathrm{m})$ and an increase in fine particles which are primarily limestone. The specific surface area (Blaine fineness) of the PLC increased by $10 \%$ to $30 \%$ in comparison to the corresponding OPC to reduce the effects of dilution. SEM images were captured and showed that for the PLC system the limestone is ground finer than the cement.

The hydration reaction each material was assessed to evaluate the effects of including limestone particles in cementitious systems. Generally the PLC mortars exhibited a slightly greater heat release than the OPC (i.e., greater hydration reaction) after 7 days. Calorimetry and chemical shrinkage results indicate that these PLC materials would be able to be used interchangeably with OPC in practice as it relates to the rate of reaction. In addition, the PLC mortars exhibited similar activation energies compared to the corresponding OPCs. This would allow the maturity method to be used by INDOT for both the PLC and OPC systems.

The mechanical properties of OPC and PLC were assessed to determine the time of set, the modulus of elasticity, compressive strength, flexural strength, drying shrinkage, and restrained autogenous shrinkage. The time of set for the PLCs was on average $10 \%$ earlier than OPCs. Generally, the PLCs show an increase in compressive strength at early ages that diminishes with time, resulting in similar compressive strengths at 28 days 


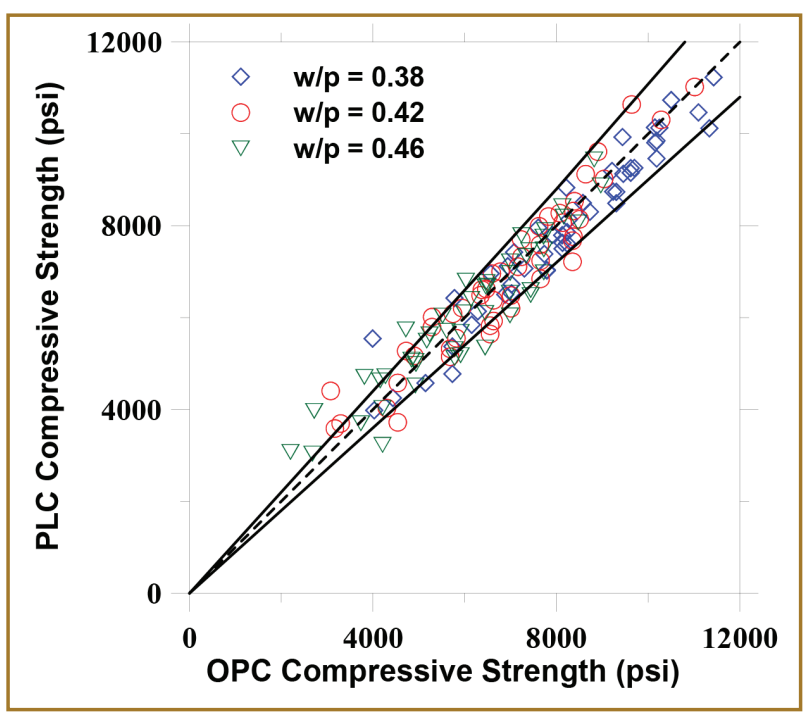

Figure 2. PLC compressive strength plotted versus each mixture's reference OPC. The dashed line indicates a 1:1 relationship, while the solid lines indicate $\pm 10 \%$.

of age. In general the elastic modulus and flexural strength of the OPC and PLC systems were similar (Figure 2). No significant change in drying shrinkage or restrained shrinkage cracking was observed for the PLC 2 when compared with OPC (Figure 3). ${ }^{2}$

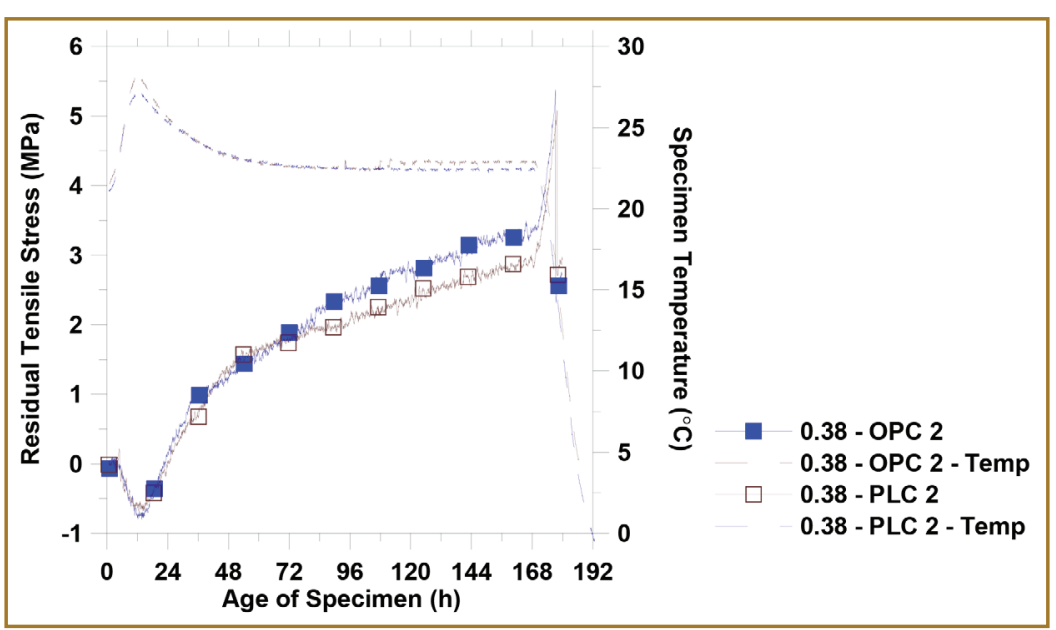

Figure 3. Tensile stress development in the dual ring test for $0.38-O P C 2$ and 0.38-PLC 2.

\section{Implementation}

Based on a review of the literature and the experiments performed in this research the following suggestions are provided for implementation.
- INDOT may consider PLC, as specified in accordance with ASTM C595/AASHTO M240, to be a suitable option for use in INDOT concrete applications.

- Ongoing research is being conducted to assess potential performance in high sulfate concentrations or in the presence of concentrated deicing salts which INDOT should monitor. Unless something negative is observed from the sulfate or deicing salt studies, PLC conforming to ASTM C 595, AASHTO M240 should be able to be used interchangeably with OPC.

- An educational module will be developed for the 2014 road school and subsequent use that introduces PLC materials to potential users. The educational module will enable INDOT personnel and INDOT contractors better understand what PLCs are and how they behave.

- INDOT is well positioned to consider using PLC on large scale paving field trials. INDOT should work with the local cement industry to identify projects that may have the potential to utilize the PLC on a coming project. The field performance of the PLC should be monitored and if the results are favorable this would provide INDOT with additional material options for paving.

\section{Notes}

1. Hooton, R., M. Nokken, M., and M. Thomas. Portland-Limestone Cement: State-of-the-Art Report and Gap Analysis for CSA A3000. Cement Association of Canada, Ottawa, Ontario, Canada, 2007; Tennis, P. D., M. D. A. Thomas, and W. J. Weiss. State-of-the-Art Report on Use of Limestone in Cements at Levels of up to $15 \%$. Portland Cement Association, Skokie, Illinois, 2011.

2. Barrett, T. J., H. Sun, C. Villiani, L. Barcello, and W. J. Weiss. Early-Age Shrinkage Behavior of Portland Limestone Cement. Concrete International, Vol. 36, No. 2, 2014.

\section{Recommended Citation}

Barrett, T. J., H. Sun, and W. J. Weiss. Performance of Portland Limestone Cements: Cements Designed to Be More Sustainable That Include up to 15\% Limestone Addition. Publication FHWA/IN/JTRP-2013/29. Joint Transportation Research Program, Indiana Department of Transportation and Purdue University, West Lafayette, Indiana, 2013. doi: $10.5703 / 1288284315335$.

View the full text of this technical report here: http://dx.doi.org/10.5703/1288284315335

Published reports of the Joint Transportation Research Program are available at http://docs.lib.purdue.edu/jtrp/.

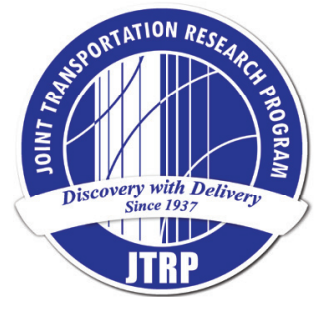

\section{PURDUE

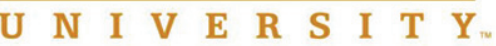

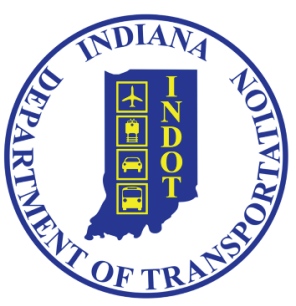

